\title{
Effects of Meteorological Variables on the Incidence of Rupture of Intracranial Aneurysms in Central New Jersey
}

\author{
Marissa Kellogg ${ }^{1}$ Dimitriy Petrov ${ }^{2} \quad$ Nitin Agarwal $^{3} \quad$ Nitesh V. Patel $^{4} \quad$ David Richard Hansberry $^{5}$
}

Prateek Agarwal $^{2}$ Michael Brimacombe ${ }^{6}$ Chirag D. Gandhi ${ }^{4}$ Charles Prestigiacomo ${ }^{4,7}$

${ }^{1}$ Department of Neurology, Oregon Health and Science University, Portland, Oregon, United States

${ }^{2}$ Department of Neurological Surgery, University of Pennsylvania, Philadelphia, Pennsylvania, United States

${ }^{3}$ Department of Neurological Surgery, University of Pittsburgh

Medical Center, Pittsburgh, Pennsylvania, United States

${ }^{4}$ Deparment of Neurological Surgery, New Jersey Medical School,

Newark, New Jersey, United States

${ }^{5}$ Department of Radiology, Thomas Jefferson University Hospitals, Philadelphia, Pennsylvania, United States

6 Department of Biostatistics, Kansas University Medical Center, Kansas City, Kansas, United States

${ }^{7}$ Department of Radiology, New Jersey Medical School, Newark, New Jersey, United States

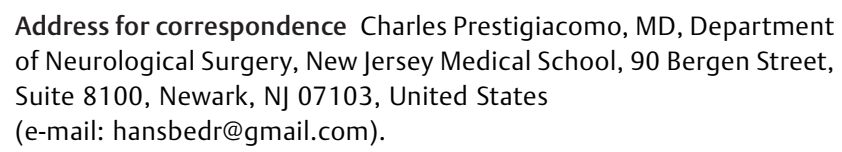

Address for correspondence Charles Prestigiacomo, MD, Department of Neurological Surgery, New Jersey Medical School, 90 Bergen Street, Suite 8100, Newark, NJ 07103, United States (e-mail: hansbedr@gmail.com).

J Neurol Surg A 2017;78:238-244.

\begin{abstract}
Keywords

- meteorological variables

- barometric pressure

- temperature

- aneurysm

- subarachnoid hemorrhage

Introduction Previous studies have suggested relationships between the rupture of intracranial aneurysms and meteorological variables such as season, barometric pressure, and temperature. Our objective was to examine the relationship between the incidence of hospital admissions secondary to aneurysmal subarachnoid hemorrhage (aSAH) and meteorological variables in central New Jersey.

Methods The study population consisted of 312 patients who presented to University Hospital in Newark, New Jersey, between January 1, 2003, and December 31, 2008, with aSAH. Days in the 6-year period were classified as nonbleed days (no aSAH), bleed days (one or more aSAHs within 1 calendar day), cluster days (two or more aSAHs within 2 calendar days), and multiple-bleed days (two or more aSAHs within 1 calendar day).

Results The only significant meteorological risk factor for the occurrence of multiplebleed days was high barometric pressure (1018.5 versus 1016.5 millibars [mbars]; $p<0.04)$, but an increase in barometric pressure (+ 2.8 mbars) over the 2 days prior to the multiple-bleed day, although not statistically significant, may be a risk factor $(p<0.09)$. Barometric pressure was also noted to be increased on bleed days (1017.2 versus 1016.5 mbars) and cluster days (1017.7 versus 1016.5 mbars), but this relationship was not significant ( $p<0.1$ and $p<0.1$, respectively). Although aSAH days demonstrated consistently lower temperatures than non-aSAH days and dropping temperatures were consistently found in the days preceding the aSAH, these relationships were not significant. Conclusion Among meteorological factors, high barometric pressure and low temperature may be risk factors for the onset of aSAH.
\end{abstract}

received

February 27, 2016

accepted after revision

April 9, 2016

published online

November 30, 2016 (c) 2017 Georg Thieme Verlag KG

Stuttgart · New York
DOI http://dx.doi.org/ 10.1055/s-0036-1594308. ISSN 2193-6315. 


\section{Introduction}

The incidence of aneurysm rupture, the clustering of such events, and the relationship to seasonal or meteorological variability continues to be heavily debated. Although a considerable number of studies have concluded there is seasonal variation to aneurysm rupture, ${ }^{1-9}$ others have refuted those claims. ${ }^{10-13}$ When studies have examined individual meteorological variables, cold temperatures and changes in atmospheric pressure are the factors most often associated with an increasing incidence of rupture, but the results vary markedly between studies. ${ }^{1,4,5,14-21}$ Atmospheric pressure is a factor of considerable debate because certain studies implicate an increase change in atmospheric pressure, others implicate a decrease change, and still others implicate an absolute change. Moreover, both high and low atmospheric pressures have been identified in separate studies as significantly associated factors to rupture. Regarding temperature, elevated temperatures have never been correlated with aneurysm rupture, yet low temperatures have been inconsistently correlated. Cowperthwaite and Burnett, in a large national multicenter study, demonstrated no correlation between nontraumatic subarachnoid hemorrhage (SAH) and seasonal and variable weather factors, the 24-hour-day changes in atmospheric conditions, and the data from the day prior to hospital admission. ${ }^{22}$

Although this study presents a significant amount of data and uses annual and moving-window standardization, days with multiple SAH and consecutive SAH occurrences were not analyzed. This limits the ability of this study to comment on the influence of atmospheric conditions on SAH clustering. The present study was designed to determine the relationship between the incidence of hospital admissions secondary to ruptured aneurysms and seasonal and meteorological variables in central New Jersey. It is distinct from prior studies of aneurysmal subarachnoid hemorrhage (aSAH) and weather variables in that it assesses differing strengths of association between certain meteorological variables and increasing temporal clustering of aSAHs, according to a method derived from that of Setzer et al. ${ }^{20}$

\section{Methods}

\section{Patient Population}

This population-based study included all patients admitted to University Hospital (UH) with SAH secondary to a ruptured intracranial aneurysm within the study period, as documented in the comprehensive neurologic database. Each case was individually chart-reviewed to verify the inclusion criteria: evidence of SAH on computed tomography imaging, angiographic evidence of an aneurysm as the source of the bleed, date of bleed (defined as day of acute symptom onset) between January 1, 2003, and December 31, 2008, and acute symptom onset occurring within 50 miles of Newark, New Jersey. Exclusion criteria included age $<18$ years, prior intracranial bleeds, prior intracranial procedures, and unknown date of acute symptom onset. Of the 354 patients in the database who met the inclusion criteria, 42 were excluded due to the exclusion criteria. A total of 312 subjects were thus included in the study.

\section{Data Collection}

Using the comprehensive neurosurgery department prospectively maintained database and the subjects' hospital charts, subject data were collected including age, hometown, diagnosis, neurologic status of patient on discharge, date of admission, the time of arrival at the hospital, date and time (if available) of acute symptom onset, and location of symptom onset. Weather data recorded at the Newark International Airport climate station between January 1, 2003, and December 31, 2008, was downloaded from the National Weather Service's National Climate Database online. Hourly, daily, and monthly measures and averages of temperature, maximum and minimum temperatures, dew point, atmospheric pressure, wind speed and direction, and precipitation were collected. Newark is located in Essex County in central New Jersey. Elevation varies from sea level to 660 feet above sea level. The average temperature ranges from $39^{\circ} \mathrm{F}$ in January to $86^{\circ} \mathrm{F}$ in July. Monthly precipitation totals range from $\sim 3$ inches in February to $\sim 4.7$ inches in July.

\section{Statistical Analysis}

All 2,190 days within the 6-year study period were classified as nonbleed days (no aSAH occurred), bleed days (one or more aSAHs occurred within 1 calendar day), cluster days (two or more aSAHs occurred within 2 calendar days) or multiplebleed days (two or more aSAHs occurred within 1 calendar day). Using Minitab software (Penn State University, State College, Pennsylvania, United States), two-sample $t$ tests were conducted for each meteorological variable on bleed days versus nonbleed days, cluster days versus noncluster days, and multiple-bleed days versus non-multiple-bleed days. Additionally, data for 1 and 2 days prior to aneurysmal rupture were also collected. The difference between the weather variables on event versus lag days was also calculated and analyzed. Univariate regression analysis was utilized. Significance was defined as a $p$ value $\leq 0.05$. Finally, the bleed, cluster, and multiple-bleed days were plotted by month to examine the data for monthly or seasonal variation.

\section{Results}

\section{Patient Characteristics}

The 312 subjects in the study had a mean age of 53 years (range: 20-88). Overall, 67\% (209) of the subjects were female, which is consistent with the established 2:1 ratio of females to males presenting with aSAH. A total of $26 \%$ of patients (82) were direct admissions to $\mathrm{UH}$; the rest were transfers from outside New Jersey or New York hospitals located within 50 miles of Newark. Overall, $25 \%$ of patients (78) had home addresses in Newark.

The neurologic status of the patients upon discharge was recorded for all but one of the 312 subjects. Fifty (16.1\%) were completely neurologically intact upon discharge, and 132 (42.4\%) returned to their previous activities with a minor neurologic deficit, whereas 70 (22.5\%) had a significant neurologic deficit. Of these, 18 (5.8\%) could perform activities of daily living (ADLs) independently, 46 (14.8\%) were dependent on others to perform ADLs, and 6 (1.9\%) were moribund. Fifty-nine (18.7\%) died in the hospital. 


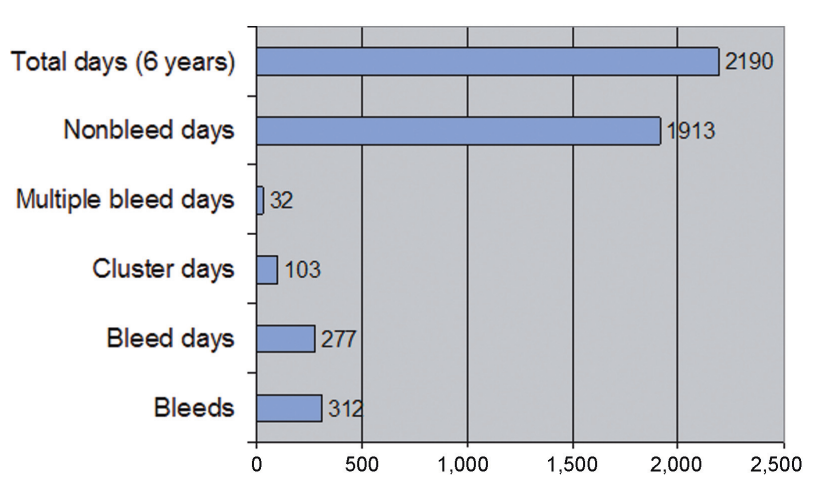

Fig. 1 Breakdown of study days.

\section{Temporal Distribution of Aneurysmal Subarachnoid Hemorrhage}

The 312 aSAHs included in the study occurred over 277 days within the 2,190-day (6-year) study period (-Fig. 1). In this study, the 277 days during which one or more patients presented to UH with aSAHs were classified as bleed days, constituting $12.6 \%$ of the study period. Of the 277 bleed days, 103 days (4.7\%) were also classified as cluster days, and 32 days (1.5\%) were classified as multiple-bleed days. There were 1,913 nonbleed days (87.4\%) within the study period during which no patient with an aSAH ultimately presented to $\mathrm{UH}$.

The incidence of aSAHs in this 6-year study was greater in the months of September through February, and lesser in the months of March through June (-Fig. 2). The peak number of bleed days per month was 33 in September and December, and the fewest number of bleed days was 20 in April and May. The number of cluster days per month peaked at 15 in October and dropped to a nadir of 4 in April. The peak number of multiple-bleed days was 6 in December, and there were zero multiple-bleed days in March.

\section{Univariate Analysis of Atmospheric Pressure}

The study demonstrated a statistically significant association between mean atmospheric pressure and the incidence of multiple-bleed days (-Table 1 ). Multiple-bleed days had a mean atmospheric pressure of 1,018.51 millibars (mbars), and non-multiple-bleed days had a mean atmospheric pres-

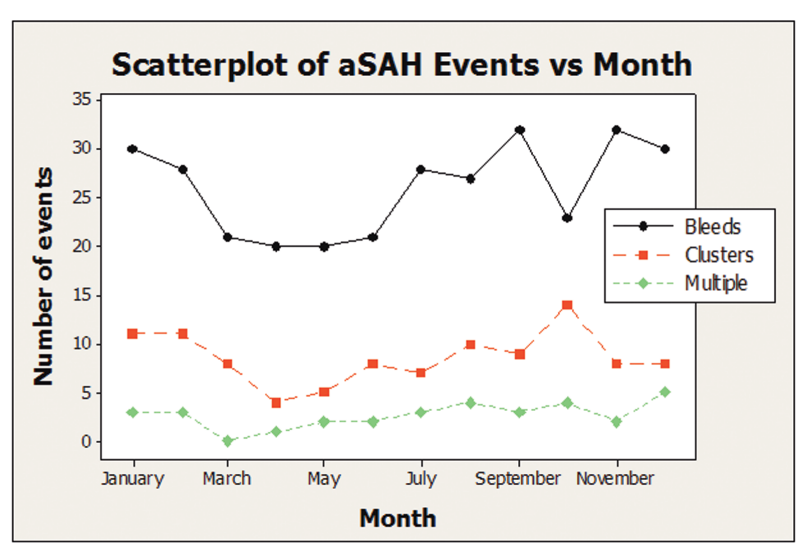

Fig. 2 Aneurysmal subarachnoid hemorrhage events by month. sure of 1,016.53 mbars $(p<0.04)$. A strong trend of higher atmospheric pressure on bleed days versus nonbleed days $(1,017.2$ versus $1,016.5 ; p<0.1)$ and cluster days versus noncluster days $(1,017.7$ versus $1,016.5 ; p<0.1)$ also existed, but these relationships were not significant.

Time-series analysis of atmospheric pressure, although not statistically significant, suggested a change in mean atmospheric pressure in the 2 days preceding multiple-bleed days (-Table 2). Mean atmospheric pressure increased 2.8 mbars over the 2 days preceding multiple-bleed days, yet before non-multiple-bleed days, pressure decreased to 0.1 mbars $(p<0.09)$. A consistent increase in pressure was noted over the 2 days preceding bleed days $(+0.6$ versus $-0.1 ; p<0.3$ ) and cluster days $(+0.7$ versus $-0.0 ; p<0.5)$, but these relationships were not significant.

\section{Univariate Analysis of Temperature}

There was no statistically significant relationship between mean temperature and incidence of bleed, cluster, or multiple-bleed days; however, the mean temperature was consistently decreased on aSAH days ( $\mathbf{-}$ Tables $\mathbf{1}$ and $\mathbf{3}$ ). Bleed days had a mean temperature of $54.36^{\circ} \mathrm{F}$; nonbleed days had a mean temperature of $55.33^{\circ} \mathrm{F}(p<0.4)$. Cluster days had a mean temperature of $53.1^{\circ} \mathrm{F}$ versus noncluster days with $55.3^{\circ} \mathrm{F}(p<0.3)$. Multiple-bleed days had a mean temperature of $53.6^{\circ} \mathrm{F}$ versus noncluster days with $55.2^{\circ} \mathrm{F}(p<0.6)$.

Similarly, there was no statistically significant change in mean temperature in the 2 days preceding aSAH days, yet there was a consistent decrease in temperature ( - Table 3 ). This relationship in the 2 days preceding multiple-bleed days was as follows: -2.1 versus $+0.0(p<0.08)$. On bleed days $(-0.5$ versus $0.1 ; p<0.3)$ and cluster days $(-0.2$ versus 0.0 ; $p<0.8$ ), the relationship was weak.

Of note, temperature range was significantly decreased on bleed days and cluster days, but not on multiple-bleed days ( - Tables 1 and 4 ). The temperature range was $19.3^{\circ} \mathrm{F}$ versus $20.1^{\circ} \mathrm{F}$ on bleed days versus nonbleed days $(p<0.05)$ and $18.7^{\circ} \mathrm{F}$ versus $20.0^{\circ} \mathrm{F}$ on cluster days versus noncluster days $(p<0.03)$. On multiple-bleed days versus non-multiplebleed days, temperature range was $18.5^{\circ} \mathrm{F}$ versus $19.9^{\circ} \mathrm{F}$ $(p<0.2)$. In the 2 days preceding aSAH days, the range consistently decreased but was not statistically significant.

Univariate Analysis of Other Meteorological Variables The study also examined the relationship of dew-point temperature, wind speed, minimum and maximum temperatures, and total precipitation to the incidence of bleed days, cluster days, and multiple-bleed days (-Table $\mathbf{1}$ ). There was no statistically significant association between any of these variables and aSAH days, or for the change in the variables in the 2 days preceding aSAH days.

\section{Correlation between Temperature and Pressure}

A cross-correlation was conducted to examine the degree to which temperature and pressure are correlated in the study data (-Fig. 3). It demonstrated an inverse relationship between temperature and pressure in the data: for every 1 mbar increase in pressure, the temperature tended to decrease by $\sim 0.2^{\circ} \mathrm{F}$. 
Table 1 Weather variables on bleed days versus nonbleed days, cluster days versus noncluster days, and multiple-bleed versus nonmultiple-bleed days

\begin{tabular}{|l|l|l|l|l|l|l|l|l|l|}
\hline Weather variable & $\begin{array}{l}\text { Bleed } \\
\text { day } \\
\text { mean }\end{array}$ & $\begin{array}{l}\text { Nonbleed } \\
\text { mean }\end{array}$ & $\begin{array}{l}t \text { test } \\
p \text { value }\end{array}$ & $\begin{array}{l}\text { Cluster } \\
\text { day } \\
\text { mean }\end{array}$ & $\begin{array}{l}\text { Noncluster } \\
\text { mean }\end{array}$ & $\begin{array}{l}t \text { test } \\
p \text { value }\end{array}$ & $\begin{array}{l}\text { Multi- } \\
\text { bleed } \\
\text { mean }\end{array}$ & $\begin{array}{l}\text { Non-multi- } \\
\text { bleed mean }\end{array}$ & $\begin{array}{l}t \text { test } \\
p \text { value }\end{array}$ \\
\hline $\begin{array}{l}\text { Mean pressure, } \\
\text { mbars }\end{array}$ & $1,017.2$ & $1,016.5$ & 0.132 & $1,017.66$ & $1,016.50$ & 0.105 & $1,018.51$ & $1,016.53$ & 0.044 \\
\hline $\begin{array}{l}\text { Mean } \\
\text { temperature, F }\end{array}$ & 54.36 & 55.33 & 0.403 & 53.1 & 55.3 & 0.254 & 53.6 & 55.2 & 0.621 \\
\hline $\begin{array}{l}\text { Mean dew-point } \\
\text { temperature, F }\end{array}$ & 40.01 & 41.15 & 0.362 & 39.0 & 41.1 & 0.307 & 38.8 & 41.0 & 0.551 \\
\hline Wind speed, mph & 8.58 & 8.51 & 0.717 & 8.55 & 8.52 & 0.904 & 9.09 & 8.51 \\
\hline $\begin{array}{l}\text { Minimum } \\
\text { temperature, F }\end{array}$ & 45.3 & 45.9 & 0.633 & 44.4 & 45.9 & 0.410 & 45.1 & 45.8 & 0.268 \\
\hline $\begin{array}{l}\text { Maximum } \\
\text { temperature, F }\end{array}$ & 64.6 & 65.9 & 0.279 & 63.0 & 65.9 & 0.152 & 63.6 & 65.8 \\
\hline $\begin{array}{l}\text { Temperature } \\
\text { range, F }\end{array}$ & 19.27 & 20.06 & 0.05 & 18.67 & 20.03 & 0.033 & 18.49 & 19.9 \\
\hline $\begin{array}{l}\text { Total } \\
\text { precipitation, } \\
\text { inches }\end{array}$ & 0.480 & 0.405 & 0.844 & 0.161 & 0.430 & 0.034 & 0.182 & 0.42 & 0.175 \\
\hline
\end{tabular}

Table 2 Time-series data of atmospheric pressure

\begin{tabular}{|c|c|c|c|c|c|}
\hline & Same day & 1 day prior & 2 days prior & Diff 1 day & Diff 2 days \\
\hline Bleed day & $1,017.2$ & $1,016.79$ & $1,016.61$ & 0.39 & 0.58 \\
\hline Nonbleed day & $1,016.5$ & $1,016.52$ & $1,016.56$ & -0.06 & -0.09 \\
\hline$p$ value & 0.132 & 0.537 & 0.910 & 0.279 & 0.291 \\
\hline Cluster day & $1,017.66$ & $1,017.53$ & $1,016.97$ & 0.14 & 0.69 \\
\hline Noncluster day & $1,016.50$ & $1,016.51$ & $1,016.54$ & -0.01 & -0.04 \\
\hline$p$ value & 0.105 & 0.123 & 0.533 & 0.830 & 0.464 \\
\hline Multiple day & $1,018.51$ & $1,017.53$ & $1,015.67$ & 0.98 & 2.84 \\
\hline Nonmultiple & $1,016.53$ & $1,016.54$ & $1,016.58$ & -0.02 & -0.05 \\
\hline$p$ value & 0.044 & 0.331 & 0.499 & 0.353 & 0.088 \\
\hline
\end{tabular}

Table 3 Time-series data of mean temperature

\begin{tabular}{|l|l|l|l|l|l|}
\hline & Same day & 1 day prior & 2 days prior & Diff $\mathbf{1}$ day & Diff 2 days \\
\hline Bleed day & 54.36 & 54.8 & 54.8 & -0.42 & -0.46 \\
\hline Nonbleed day & 55.33 & 55.3 & 55.3 & 0.05 & 0.06 \\
\hline$p$ Value & 0.403 & 0.671 & 0.688 & 0.200 & 0.320 \\
\hline Cluster day & 53.1 & 53.5 & 53.3 & -0.37 & 0.01 \\
\hline Noncluster day & 55.3 & 55.3 & 55.3 & 0.516 & 0.15 \\
\hline$p$ value & 0.254 & 0.362 & 55.7 & -1.31 & 0.841 \\
\hline Multiple day & 53.6 & 54.9 & 55.2 & 0.01 & -2.14 \\
\hline Nonmultiple & 55.2 & 55.2 & 0.884 & 0.252 & 0.03 \\
\hline$p$ value & 0.621 & 0.923 & & 0.084 \\
\hline
\end{tabular}


Table 4 Time-series data of temperature range

\begin{tabular}{|c|l|l|l|l|l|}
\hline & Same day & 1 day prior & 2 days prior & Diff 1 day & Diff 2 days \\
\hline Bleed day & 19.27 & 19.72 & 19.81 & -0.45 & -0.53 \\
\hline Nonbleed day & 20.06 & 20.00 & 19.99 & 0.06 & 0.07 \\
\hline$p$ value & 0.05 & 0.517 & 0.654 & 0.265 & 0.256 \\
\hline Cluster day & 18.67 & 19.91 & 20.08 & -1.24 & -1.41 \\
\hline Noncluster day & 20.03 & 19.97 & 19.96 & 0.06 & 0.07 \\
\hline$p$ value & 0.033 & 0.926 & 0.855 & 0.058 & 0.100 \\
\hline Multiple day & 18.49 & 20.55 & 18.96 & -2.06 & -0.47 \\
\hline Nonmultiple & 19.9 & 19.96 & 19.98 & 0.03 & 0.00 \\
\hline$p$ value & 0.175 & 0.571 & 0.369 & 0.062 & 0.766 \\
\hline
\end{tabular}

\section{Discussion}

The results of the study suggest that high atmospheric pressure may be a risk factor for aSAH. There is a statistically significant association between mean atmospheric pressure and the incidence of multiple-bleed days $(p<0.04)$, as well as a trend observed for the change in mean atmospheric pressure over the 2 days preceding a multiple-bleed day. Moreover, there is a consistent and increasingly strong relationship between high atmospheric pressure and increasing temporal clustering of aSAHs, as demonstrated by the decreasing $p$ values from bleed days $(p<0.1)$ to cluster days $(p<0.1)$ to multiple-bleed days $(p<0.04)$. The conclusion that high atmospheric pressure may be a risk factor for aSAH is in agreement with several studies but at odds with others. Indeed, several studies implicate a change in atmospheric pressure as a risk factor but not a directional change.

The results of this study also suggest that low temperatures may be associated with increased incidence of aSAH. Although the relationship between temperature and aSAH was not significant, the data demonstrated a consistent trend linking decreased temperatures and increased incidence of aSAH. The link between decreased temperatures and aSAH has been significant in several prior studies, but not significant in

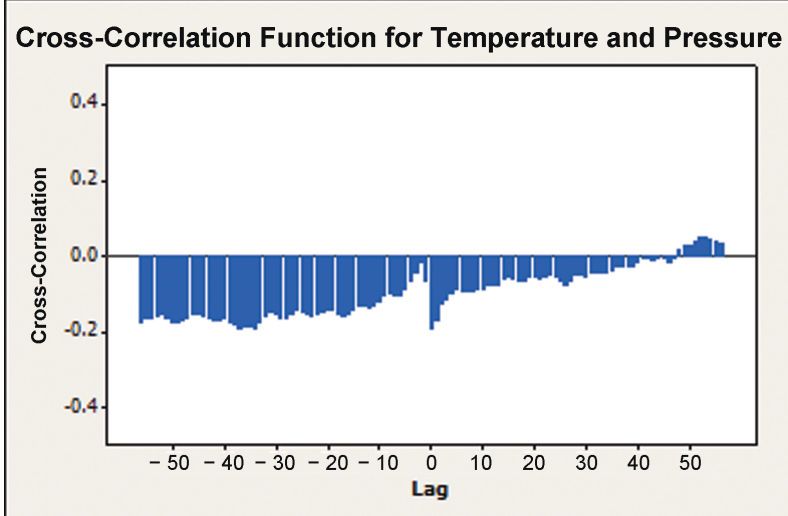

Fig. 3 Correlation of temperature and pressure. many others. The statistically significant relationship between decreased temperature range and bleed and cluster days was unexpected and not noted elsewhere in the literature.

This retrospective hospital-based study has several limitations. The first limitation is the low number of cases at 312 subjects. Despite the low number, the association between atmospheric pressure and multiple-bleed days was significant; yet with more cases and greater power, the strong consistent trends that linked atmospheric pressure and bleed or cluster days, as well as low temperatures and aSAH days, would likely have become significant. Given that many patients with aSAH do not survive to reach the hospital, hospital-based studies are not inclusive of all patients presenting with aSAH in their catchment area. In addition, the geographic catchment area of hospitals is not rigid, and ambulances might transport patients to one of several different hospitals. Furthermore, three quarters of the patients in this study were transfers from outside hospitals. Transfers introduce significant bias into the study because these patients most often come from outside the geographic catchment area, and patterns of transfer often depend on transferring physician preference, hospital bed availability, accepting physician availability, and so on. As a retrospective study that required extensive chart review to determine dates, times, circumstances, and locations of bleeds, precise identification of these factors are more conducive to error. Finally, given the low case numbers and inability to gather certain comprehensive data retrospectively, adequate subgroup analysis and multivariate analysis were not possible.

Most of the literature on weather and SAH has several shortcomings. Most studies involve only region or population. Also, previous studies have included low numbers of subjects, usually falling in the 60 to 600 case range, with two exceptions: 1,729 and $7,758 .^{14,22}$ Authors have also omitted to note hourly changes in the data. Only one study examined hourly meteorological data and conducted a time-series analysis using autoregressive integrated moving average (ARIMA) modeling. ${ }^{14}$ Also, factors that have been implicated in causing aneurysmal rupture, including Valsalva maneuver and straining, have not been controlled for and may serve as significant confounders. A large-scale prospective regionally based study is needed to best examine the relationship 
between aSAH and meteorological variables. Given the disparate results of studies conducted in different locations around the world, it is likely that inherent weather differences complicate the issue and prevent fair comparisons from being made, necessitating a multicenter study design.

In addition to collecting standard demographic data and evaluating for established aneurysmal risk factors, three critical questions must be addressed for each case included in the study: date and time (within an hour, ideally) of acute symptom onset, circumstances preceding symptom onset (e.g., Valsalva maneuver, uncontrolled blood pressure, etc.), and exact location of acute symptom onset. Cowperthwaite et al established a large-scale retrospective precedent for elucidating the relationship of atmospheric variables with $\mathrm{SAH}^{22}$ Because of the potential public health repercussions, a prospective study of similar size and scope is necessary. For example, if increased atmospheric pressures were demonstrated to increase risk of rupture, it might lead investigators to examine models of aneurysm rupture at different external pressures to study the vasculature's response to such stress. Perhaps certain inflammatory mediators are upregulated under increased atmospheric pressure, triggering a cascade of events that increase incidence of rupture. Indeed, several studies have demonstrated that decreased ambient temperatures predispose patients to increased blood pressure, hypothetically leading to an increased incidence of vascular events. ${ }^{23-27}$ Conversely, if we identify certain meteorological factors as risk factors of rupture, hospitals could increase their readiness for vascular events on certain days or medical industry retailers could better prepare their inventory.

\section{Conclusion}

Based on the results of the study, high barometric pressure may be a risk factor for aSAH. Although the relationship between temperature and aSAH incidence was not statistically significant, there existed a consistent trend in the data suggesting low temperature may also be a risk factor for aSAH. Large-scale prospective regionally based studies are necessary to further elucidate the relationship between meteorological variables, season, and aSAH incidence. The mechanisms underlying any associations between meteorological variables and aneurysmal rupture have yet to be established.

\section{References}

1 Chyatte D, Chen TL, Bronstein K, Brass LM. Seasonal fluctuation in the incidence of intracranial aneurysm rupture and its relationship to changing climatic conditions. J Neurosurg 1994;81(4): 525-530

2 Gallerani M, Portaluppi F, Maida G, et al. Circadian and circannual rhythmicity in the occurrence of subarachnoid hemorrhage. Stroke 1996;27(10):1793-1797

3 Inagawa T. Seasonal variation in the incidence of aneurysmal subarachnoid hemorrhage in hospital- and community-based studies. J Neurosurg 2002;96(3):497-509
4 Jehle D, Moscati R, Frye J, Reich N. The incidence of spontaneous subarachnoid hemorrhage with change in barometric pressure. Am J Emerg Med 1994;12(1):90-91

5 Lejeune JP, Vinchon M, Amouyel P, Escartin T, Escartin D, Christiaens JL. Association of occurrence of aneurysmal bleeding with meteorologic variations in the north of France. Stroke 1994;25(2): 338-341

6 Muroi C, Yonekawa Y, Khan N, Rousson V, Keller E. Seasonal variations in hospital admissions due to aneurysmal subarachnoid haemorrhage in the state of Zurich, Switzerland. Acta Neurochir (Wien) 2004;146(7):659-665

7 Ostbye T, Levy AR, Mayo NE; The Canadian Collaborative Study Group of Stroke Hospitalizations. Hospitalization and case-fatality rates for subarachnoid hemorrhage in Canada from 1982 through 1991. Stroke 1997;28(4):793-798

8 Rosenørn J, Rønde F, Eskesen V, Schmidt K. Seasonal variation of aneurysmal subarachnoid haemorrhage. Acta Neurochir (Wien) 1988;93(1-2):24-27

9 Vinall PE, Maislin G, Michele JJ, Deitch C, Simeone FA. Seasonal and latitudinal occurrence of cerebral vasospasm and subarachnoid hemorrhage in the Northern Hemisphere. Epidemiology 1994; 5(3):302-308

10 Inagawa T, Aoki H, Ishikawa S, Takahashi M, Yoshimoto H. Aneurysmal subarachnoid hemorrhage in Izumo City and Shimane Prefecture of Japan: seasonal variation. . Hiroshima J Med Sci Mar 1988;37(1):17-18

11 Inagawa T, Takechi A, Yahara K, et al. Primary intracerebral and aneurysmal subarachnoid hemorrhage in Izumo City, Japan. Part I: Incidence and seasonal and diurnal variations. J Neurosurg 2000; 93(6):958-966

12 Rothwell PM, Wroe SJ, Slattery J, Warlow CP. Is stroke incidence related to season or temperature? The Oxfordshire Community Stroke Project. Lancet 1996;347(9006):934-936

13 Schievink WI, Wijdicks EF, Meyer FB, Piepgras DG, Fode NC, Whisnant JP. Seasons, snow, and subarachnoid hemorrhage: lack of association in Rochester, Minnesota. J Neurosurg 1995;82(5):912-913

14 Abe T, Ohde S, Ishimatsu S, et al. Effects of meteorological factors on the onset of subarachnoid hemorrhage: a time-series analysis. J Clin Neurosci 2008;15(9):1005-1010

15 Beseoglu K, Hänggi D, Stummer W, Steiger HJ. Dependence of subarachnoid hemorrhage on climate conditions: a systematic meteorological analysis from the Dusseldorf metropolitan area. Neurosurgery 2008;62(5):1033-1038; discussion 1038-1039

16 Buxton N, Liu C, Dasic D, Moody P, Hope DT. Relationship of aneurysmal subarachnoid hemorrhage to changes in atmospheric pressure: results of a prospective study. J Neurosurg 2001;95(3):391-392

17 Landers AT, Narotam PK, Govender ST, van Dellen JR. The effect of changes in barometric pressure on the risk of rupture of intracranial aneurysms. Br J Neurosurg 1997;11(3):191-195

18 Law HY, Wong GK, Chan DT, Wong L, Poon WS. Meteorological factors and aneurysmal subarachnoid haemorrhage in Hong Kong. Hong Kong Med J 2009;15(2):85-89

19 Oyoshi T, Nakayama M, Kuratsu J. Relationship between aneurysmal subarachnoid hemorrhage and climatic conditions in the subtropical region, Amami-Oshima, in Japan. Neurol Med Chir (Tokyo) 1999;39(8):585-590; discussion 590-591

20 Setzer M, Beck J, Hermann E, et al. The influence of barometric pressure changes and standard meteorological variables on the occurrence and clinical features of subarachnoid hemorrhage. Surg Neurol 2007;67(3):264-272; discussion 272

21 de Steenhuijsen Piters WA, Algra A, van den Broek MF, Dorhout Mees SM, Rinkel GJ. Seasonal and meteorological determinants of aneurysmal subarachnoid hemorrhage: a systematic review and meta-analysis. J Neurol 2013;260(2):614-619

22 Cowperthwaite MC, Burnett MG. The association between weather and spontaneous subarachnoid hemorrhage: an analysis of 155 US hospitals. Neurosurgery 2011;68(1):132-138; discussion 138-139 
244 Association of Meteorological Variables and Aneurysm Rupture Kellogg et al.

23 Jehn M, Appel LJ, Sacks FM, Miller ER III; DASH Collaborative Research Group. The effect of ambient temperature and barometric pressure on ambulatory blood pressure variability. Am J Hypertens 2002;15(11):941-945

24 Modesti PA, Morabito M, Bertolozzi I, et al. Weather-related changes in 24-hour blood pressure profile: effects of age and implications for hypertension management. Hypertension 2006;47(2):155-161

25 Kristal-Boneh E, Harari G, Green MS. Seasonal change in 24-hour blood pressure and heart rate is greater among smokers than nonsmokers. Hypertension 1997;30(3 Pt 1):436-441
26 Kristal-Boneh E, Harari G, Green MS, Ribak J. Seasonal changes in ambulatory blood pressure in employees under different indoor temperatures. Occup Environ Med 1995;52(11): 715-721

27 Winnicki M, Canali C, Accurso V, Dorigatti F, Giovinazzo P, Palatini P. Relation of 24-hour ambulatory blood pressure and short-term blood pressure variability to seasonal changes in environmental temperature in stage I hypertensive subjects. Results of the Harvest Trial. Clin Exp Hypertens 1996;18(8): 995-1012 